\title{
A ABEn E O PIPMO NO PREPARO DO ATENDENTE DE ENFERMAGEM — RELATO DE UMA EXPERIENCIA
}

\author{
* Maria José Arléo Barbosa Amorin
}

RBEn/06

AMORIM, M. J. A. B. - A ABEn e o PIPMO no preparo do atendente de enfermagem relato de uma experiência. Rev. Bras. Enf.; DF, 32 : 183-212, 1979.

\section{INTRODUÇĀO}

A Associaçāo Brasileira de Enfermagem (ABEn), seção da Bahia, manteve os seus primeiros contatos com o Programa Intensivo de Preparação de Mãode-Obra (PIPMO) em 1971, quando tomou conhecimento da existência de vários cursos de atendente de enfermagem patrocinados por esse órgão, não programados e nem ministrados necessariamente por enfermeiras.

Inicialmente, a ABEn propôs a canalizaçāo dos recursos destinados ao preparo do Atendente de Enfermagem para cursos de Auxiliar de Enfermagem, considerando a grande demanda desta categoria de pessoal no mercado de trabalho em todo o Estado. Diante das objeções apresentadas por motivos diversos pelo PIPMO, a ABEn decidiu assumir os referidos cursos, responsabilizando-se por sua programação e execuçāo.
O presente trabalho relata a forma utilizada para a absorçāo pela ABEn de todos os cursos programados dentro da área, apresenta os passos do planejamento do curso, desde os contatos iniciais com diversas entidades até à avaliação. Finalmente, apresenta uma conclusão onde ressalta a importância do convênio e faz algumas recomendações para as seções da Associação Brasileira de Enfermagem.

A autora deixa explícito que sem c otimismo, o entusiasmo e o esforço da então Presidente da ABEn, Jandyra Santos Orrico, não teria sido possível naquela oportunidade a execução do planejamento apresentado, ressalta também o relevante apoio da colega Rosamaria Silva Nuñez que foi atuante nāo somente como instrutora de vários cursos mas também, como colaboradora na coordenaçāo de alguns. A ex-tesoureira da ABEn, Eunice Marinho Alcântara, foi incentivadora da realizaçāo

- Assistente da chefia do Serviço de Enfermagem do Hospital Ana Nery.

Coordenadora dos cursos promovidos pela ABEn em Convênio com o PIPMO.

- Trabalho apresentado ao XXX Congresso Brasileiro de Enfermagem.

Belém - Pará - 16 a 22/07/79 - Tema livre. 
AMORIM, M. J. A. B. - A ABEn e o PIPMO no preparo do atendente de enfermagem relato de uma experiência. Rev. Bras. Enf.; DF, 32 : 183-212, 1979.

dos cursos e muito calobarou na execução dos mesmos. Finalmente, ficam aqui expressos os agradecimentos à atual Presidente, Anaita Oliveira Costa, pela confiança depositada nesta coordenação e pela motivação em continuar com o Convênio em busca de aperfeiçoar cada vez mais o planejamento e execução dos cursos.

\section{I - MOTIVOS DA REALIZAÇĀO DO CONVÊNIO ABEn-Ba./PIPMO}

O I Plano Nacional de Desenvolvimento Econômico e Social no capítulo referente à "Política de Aproveitamento dos Recursos Humanos do País", compreende a realização do programa intensivo de preparação de mão-de-obra, no processo de uma educação permanente.

Criado em 1964, o Programa Intensivo de Preparação de Mão-de-Obra (PIPMO), órgão do Ministério da Educação e Cultura, tem sido um agente catalizador, unindo Instituições, conjugando esforços de órgãos Públícos e de iniciativa privada, no sentido de ativar a preparação da mão-de-obra.

Os contatos iniciais da Associação Brasileira de Enfermagem, seção da Bahia, com o PIPMO surgiram em 1971 em decorrência de irregularidades observadas no que se refere ao preparo de pessoal auxiliar de enfermagem.

A ABEn documentada com vários certificados de Auxiliar de Enfermagem expedidos pelo PIPMO, cujo preparo fol efetuado em cento e cinquienta horas, pôde, em visita previamente programada, ouvir os argumentos dos seus dirigentes e em seguida informar sobre os niveis de enfermagem, alertando para possíveis implicações que um elemento da equipe de enfermagem, mal preparado e mal conduzido, pode acarretar à Comunidade. Os referidos cursos, espalhados por todo o Estado da Bahia, não eram programados nem ministrados necessariamente por enfermeiras, foi constatada a participação de estudantes de Medicina e de profissionais de outras áreas em quase sua totalidade.

O PIPMO não apresentou objeção quanto à modificação na denominação do curso, mas referiu dificuldades quanto a não participação de outros elementos nos cursos, esclarecendo que sua maior preocupação estava voltada para o atendimento do programa estabelecido pelo órgão Central e as entidades até então convenentes não dispunham de enfermeiras. Para evitar a continuidade daquele procedimento, a ABEn, resolveu assumir todos os cursos propostos nesta área, responsabilizandose por sua programação e execução.

Em tentativa anterior, porém infrutífera, a ABEn propôs ao PIPMO a canalização dos recursos destinados ao preparo do atendente de enfermagem para cursos de Auxiliar de Enfermagem com carga horária de 850 horas, exclusivamente profissionalizante para candidatos que tivessem concluído o primeiro grau, o que posteriormente foi recomendação do Seminário sobre Avaliação do Projeto Formação de Auxíliar de Enfermagem do Ministério da Saúde em convênio com outros órgãos, realizado em Recife em dezembro de 1973.

Diante do exposto, procurando atuar em sintonia com os objetivos do Governo Federal, quando volta sua atenção para o preparo de pessoal à curto prazo, principalmente na área de saúde, a ABEn decidiu aceitar o cumprimento de mais uma atividade que veio ampliar as prerrogativas de sua diretoria.

Por sua vez, foram atendidos oportunamente, não só os insistentes e renovados pedidos do pessoal que já trabalhava em hospitais sem as mínimas conđições, como também as solicitaçōes de diversas Entidades Sociais que pretendiam incluir na sua programaçāo. 
AMORIM, M. J. A. B. - A ABEn e o PIPMO no preparo do atendente de enfermagem relato de uma experiência. Rev. Bras. Enf.; DF, 32 : 183-212, 1979.

cursos da área da saúde coordenados e ministrados por profissional competente .Vale ressaltar que no Estado da Bahia e até mesmo em Salvador, o número de auxiliares de enfermagem preparado anualmente não atende a grande demanda do mercado de trabalho. Por isso foram consideradas também as solicitações que diversos hospitais e Casas de Saúde particulares faziam a colegas e associados no sentido de conseguirem pessoal com algum treinamento para os seus serviços.

\section{II - PLANEJAMENTO DOS CURSOS}

A competência da organização destes cursos foi entregue à coordenadora da Comissão de Legislação, considerando que suas atividades profissionais naquela época eram voltadas para o ensino de enfermagem em nível médio.

$O$ número de turmas tem sido planejado de acordo com a programação orçamentária anual permitida pelo PIPMO. Neste planejamento, são incluidos vários cursos de Atualizaçāo para auxiliares de enfermagem de diversos hospitais de Salvador, com treinamento específico em Enfermagem MédicoClrúrgica, Pediályica, Obstétrica e de Saúde Pública. Por necessidade local, foi realizado também um curso de $\mathrm{Au}$ xiliar de Enfermagem do Trabalho com efeitos evidentemente satisfatórios. A canalização de verbas para todos estes cursos de grande utilidade para a Comunidade proporcionou uma redução no número de cursos de atendente de enfermagem, possibilitando conseqüentemente o comando de todos eles pela ABEn.

Durante estes sete anos foram preparadas trinta e sete turmas de atendentes de enfermagem, perfazendo um to.tal de novecentos e dois atendentes, o que corresponde a uma média de vinte e quatro alunos por turma.
A persistência do Convênio ABEnBa./PIPMO e a realização eficiente dos cursos de atendentes de enfermagem, têm sido possíveis em decorrência de um trabalho que envolve uma série de pessoas e de medidas e, exige muito cuidado no cumprimento de cada fase do processo. As resistências apresentadas por várias colegas que pareciam não entender ainda aquela justa e cnrajosa atitude da Associação de Classe, constituiu mais um obstáculo superado também com os esforços unidos de colegas mais otimistas.

Quanto ao planejamento, organização e controle, a Coordenação dos cursos de Atendente de Enfermagem programou atividades que constituem um todo harmônico, conduzindo a resultados qoe. satisfazem plenamente os objetivos propostos. Estas atividades referem-se a contatos com o PIPMO, Entidades diversas e Hospitais, divulgação, inscrição, seleção, reuniōes com instrutoreã, desenvolvimento do programa e avaliação.

1 - Contatos da Coordenação com o PIPMO, Entidades Diversas e Hospitais

Os termos do Convênio ABEn-PIPMO, são renovados anualmente e por esta razão os entendimentos são realizados nos primeiros dias do mês de janeiro.

Nesta mesma época, são promovidos contatos com determinadas Entidades espalhadas por diversos bairros da cidade como Centros Sociais, Abrigos, Asilos, Orfanatos e etc., e selecionadas aquelas que apresentam condiçōes para a realização dos cursos. As entidades interessadas solicitam os cursos e posteriormente são visitadas pela coordenadora que inspeciona o local, aprovando-o, caso atenda aos requisitos previamente estipulados, como sala de aula com os equipamentos mínimos indispensáveis, sala de técnica, contendo 
AMORIM, M. J. A. B. - A ABEn e o PIPMO no preparo do atendente de enfermagem relato de uma experiência. Rev. Bras. Enf.; DF, $32: 183-212,1979$.

materiais que correspondem a uma unidade do paciente (cama, colchão, travesseiro, mesa de cabeceira e cadeira!, condiçōes de conservação destas salas (ordem, limpeza, iluminação e ventilação), disponibilidade quanto ao horário e data programadas e participação de uma pessoa nas atividades de apoio, quando necessário. Considerando que algumas destas entidades já dispõem de determinados materiais didáticos e de consumo, somente após a realização destas visitas, é encaminhada com um pedido de providências à Tesouraria da ABEn a relação do material necessário para cada curso. (Anexo n..$^{\circ} 01$ ).

Nesta ocasiāo, são expedidos ofícios aos hospitais gerais, solicitando oportunidade de estágio para os alunos do curso, cuja data de realização é planejada com antecedência, obedecendo na medida do possível o cronograma traçado no início do mês de janeiro.

Firmado o Convênio e mantidos os contatos com as entidades e hospitais, a coordenação volta ao PIPMO, apresentando desta vez um ante-projeto com os seguintes dados: número de turmas, locais com endereços para sua realização, horários de aulas, hospitais que serão utilizados como campo de estágio, datas do início e término de cada curso.

\section{2 - Divulgação}

Enquanto as mencionadas atividades burocráticas e administrativas estāo sendo realizadas, as entidades eleitas sob a supervisão da coordenadora, fazem o trabalho de divulgação, utilizando os seus próprios recursos, principalmente através de comunicação aos associados, cartazes e distribuição de pequenos anúncios. Outro meio é a promoção, altamente positiva, realizada pelos próprios alunos que participaram do curso anterior junto aos seus amigos e pessoas da comunidade. Os fun- cionários sem preparo que trabalham nos hospitais onde os alunos fazem estágios são possíveis candidatos às próximas turmas. Geralmente, algumas religiosas participam dos cursos e nos seus trabalhos de comunidade fazem a divulgação com acentuado interesse.

\section{3 - Inscrição}

Os trabalhos de ínscrição fícam a cargo de um funcionário de apoio da entidade sob a supervisão da Coordenadora. Geralmente, as inscriçōes são realizadas nos meses de fevereiro e agosto, visto que os cursos são preferentemente iniciados em março e setembro. São exigidos como requisitos a idade mínima de dezessete anos e meio, a apresentação da carteira de identidade e a escolaridade mínima de $5 .^{a}$ série. Devem ser reservistas e eleitores, nos casos previstos em lei quanto à idade e obrigaçōes cívicas. Neste momento, os candidatos são avisados sobre o dia e horário do teste de seleçāo.

\section{4 - Seleção dos candidatos}

O processo que seleciona entre vários indivíduos aqueles que, provavelmente melhor se ajustarão às tarefas da esfera doméstica no Serviço de Enfermagem, é um dos pontos mais difíceis para a coordenação. O número de inscritos é bem significativo e às vezes concorrem cinco candidatos a uma vaga Os atributos necessários ao ajustamento na ocupação futura tornam difícil o julgamento através de provas escritas ou orais, mas é impossivel uma seleção ideal que ofereça condiçōes de classificar as pessoas, considerando atributos físicos, sensoriais, intelectuais, sociais, de personaildade, interesse, temperamento, caráter, habilidade e destreza, memória, atenção, coordenação motora e outros. 
AMORIM, M. J. A. B. - A ABEn e o PIPMO no preparo do atendente de enfermagem relato de uma experiência. Rev. Bras. Enf.; DF, 32 : 183-212, 1979.

Diante da impossibilidade de realizar uma seleção mais eficiente, é feita a tentativa de atender em parte, algumas das exigências mais necessárias. A coordenadora tem o cuidado de conciliar as datas dos testes de seleção entre todas as entidades, considerando como atribuição nāo delegável esta atividade. A seleção inicial consta de provas de Português e Matemática (Anexos n. ${ }^{\circ}$ s 02 e 03), nāo sendo possível estabelecer uma média mínima de aprovação, o que vaí depender do nível de escolaridade de cada grupo. Há situaçōes em que todos os aprovados têm notas superiores a oitenta pontos, enquanto em outras, torna-se necessário a aproximação para sessenta pontos a fim de atingir um número razoável de alunos.

Inicialmente, houve a tentativa de não se aceitar candidatos de nível muito acima do exigido, pela dificuldade de sua fixação como atendente, o que conseqüientemente significa arrebatar oportunidades de outros elementos. Mas as condiçōes sócio-econômicas do Estado da Bahia, em que o desemprego e subemprego são fenômenos constantes, fizeram com que houvesse um retratamento neste sentido; isto ocorreu principalmente em virtude de suplicantes pedidos de pessoas que se encontravam sem as minimas perspectivas de emprego, apesar de terem concluido ou estarem cursando o segundo grau.

$\mathrm{Na}$ medida do possivel, a coordenadora faz uma sondagem para verificar quais os candidatos que já trabalharam em serviços de enfermagem; esta situação é importante e influente como critério para decidir entre indivíduos que obtém notas idênticas.

Ao concluirem as provas de Portuguès e Matemática, os candidatos já recebem a informação sobre o dia em que terão os resultados, correspondendo a um intervalo de dez dias aproximadamente.
A relação nominal dos candidatos aprovados é enviada à entidade no dia estabelecido, contendo em anexo o convite determinando o dia para a apresentação de todos.

Nesta data, há um contato mais demorado com os alunos e à medida que são revistos os seus documentos, a coordenadora faz uma ligeira entrevista com cada um, oportunidade em que observa aspectos gerais concernentes a apresentação, atitude, expressão, aspec-to higiênico, atençāo, dicção, audiçāo, etc.

\section{5 - Reuniões com as instrutoras}

As enfermeiras responsáveis pelos estágios e aulas teórico-práticas sāo orientadas pela coordenadora antes do início do curso e durante todo o seu desenvolvimento, para que haja uma metodologia uniforme, favorecendo a obtençāo dos objetivos propostos.

Considerando a quantidade de turmas realizadas anualmente, observa-se que o número de enfermeiras que integra o grupo de instrutores é bastante significativo. Na medida do possível, é mantido um mesmo grupo de trabalho, mas as dificuldades são numerosas, principalmente no que se refere à baixa remuneraçāo por hora-aula, não compensando os esforços das colegas que se ausentam da participação nos cursos, assim que surgem melhores oportunidades.

Este fato implica na necessidade de fazer um recrutamento de enfermeiras, através de convites às alunas do último semestre das Escolas de Enfermagem, de notificaçōes a colegas assíduas nas reuniōes da $A B E n$, e àquelas que trabalham em hospitais que têm um. corpo de enfermagem numeroso. exigência fundamental, sua inscrição no Conselho de Enfermagem.

Formado o grupo de colegas, seis em média, é aprazada uma reunião quan- 
AMORIM, M. J. A. B. - A ABEn e o PIPMO no preparo do atendente de enfernnagem relato de uma experiência. Rev. Bras. Enf.; DF, 32 : 183-212, 1979.

do são discutidos todos os assuntos relacionados ao curso. Os motivos do Convênio e os objetivos do curso são assuntos primordiais. apresentado e dis cutido o programa, analisada a metodologia a ser empregada nas aulas e estágios e examinados os meios de avaliação do aluno.

No final da reunião, as enfermeiras recebem uma ficha de auto-análise (Anexo n.o 04), que não será devolvida; representa apenas um instrumento para avaliação de si mesma, incentivando o aperfeiçoamento de seu desempenho.

Todas recebem uma pasta com o material necessário, incluindo programa, apostilas, revista de "Enfermagem Básica" do PIPMO e como lembrete, uma relação de instruções básicas, cujo atendimento é essencial ao bom andamento do curso.

A enfermeira instrutora compete:

- dar exemplo de assiduidade, pontualidade e dedicação aos seus deveres;

- considerar os valores éticos como imprescindíveis na formação do atendente de enfermagem;

- contribuir para estabelecer um clima de confiança, franqueza e colaboração entre si e os alunos;

- manter boa disciplina nas aulas;

- propiciar aos alunos condições favoráveis para um ensino eficiente dentro dos horários marcados, atendendo às boas normas pedagógicas e respeitando as instruçōes da coordenação;

- avisar com antecedência razoável quando impossibilitada de dar aula, para que a substituição seja providenciada em tempo.

6 - Elaboração, atualização e desenvolvimento do programa

O programa elaborado tem por base noções elementares de enfermagem, in- cluindo técnicas mais simples além das tarefas situadas no campo da esfera doméstica. $\mathrm{E}$ revisto anualmente com a finalidade de melhor atender à realidade dos serviços que absorvem a maior quantidade dos concluintes. Consta de setenta e cinco horas teóricas e duzentas e vinte e cinco horas práticas sob a forma de estágios em hospitais (Anexo n. 05).

As aulas teóricas são ministradas na própria entidade, e a demonstração é a estratégia mais utilizada, pois representa um método de grande eficiência no ensino de atividades que visam a profissionalização, principalmente em curto prazo. Além disto, é adequado a qualquer nível de aluno e seu poder de comunicação é imenso, recomendado como excelente recurso para instruir grupos heterogêneos. Em alguns assuntos, a instrutora exige a devolução de técnicas, como por exemplo, temperatura, pulso e respiração.

Os alunos recebem apostilas que foram elaboradas pela coordenadora juntamente com algumas das enfermeiras integrantes do curso. Durante três anos (72 a 74) o PIPMO forneceu a revista "Enfermagem Básica" para todos os alunos, voltando posteriormente ao sistema de apostilas.

A depender das condiçōes oferecidas por cada entidade, e da disponibilidade da enfermeira responsável pela instrução dos alunos, as aulas são ministradas diariamente ou três vezes por semana em duas ou três horas diárias. A duração desta primeira etapa é de aproximadamente dois a três meses. Os horários dispostos para estas aulas variam também de acordo com a disponibilidade das entidades. A grande maioria dos cursos tem sido realizada à tarde (vinte e oito) enquanto que houve apenas duas turmas pela manhã e sete à noite.

Diariamente, antes de iniciar a aula. é feito um controle de freqüência, pela 
AMORIM, M. J. A. B. - A ABEn e o PIPMO no preparo do atendente de enfermagem relato de uma experiência. Rev. Bras. Enf.; DF, 32 :183-212, 1979.

instrutora que utiliza uma folha apropriada neste mesmo impresso, são anotados os assuntos ministrados com sua assinatura. Não é permitido ao aluno que tenha mais de vinte por cento de faltas nas aulas teórico-práticas, realizar estágio, sendo automaticamente eliminado do curso.

Para facilitar a resolução de alguns assuntos relacionados ao grupo, é eleito um representante de classe que dentre outras atribuiçōes, encarrega-se também de ajudar à instrutora na organização dos recursos utilizados na aula.

Durante esta primeira etapa, a coordenadora entra em contato com a instrutora e com os alunos quantas vezes sejam necessárias. Normalmente, quando não há falha em qualquer fase do planejamento, ela se faz presente no primeiro dia, no meio e no fim do curso teórico. Inicialmente, apresenta os objetivos do curso, abordando alguns aspectos da ABEn e do PIPMO; trata também do Conselho de Enfermagem, alertando todo o grupo quanto ao seu posicionamento na legislação de enfermagem e no COREN. Na segunda oportunidade, analisa os resultados da primeira avaliação que são obtidos através da participação do aluno na aula e das provas de verificação (Anexo n.० 06); discute sobre os campos de estágios, distribuição dos grupos e modelo e cor do uniforme; a cor adotada é a azul, preferentemente em tom mais claro. Nas vésperas do estágio, a coordenadora volta a visitar o grupo, desta vez para enfatizar aspectos éticos, enfocando o comportamento no hospital e seus deveres como futuro ocupante da equipe de enfermagem.

Concluída a primeira etapa do curso, os alunos são distribuídos em grupos que variam de nove a doze treinandos para realização dos etágios nos hospitais. Cada instrutora de grupo continua exigindo a freqüência que é registrada em impresso apropriado (Anexo n. ${ }^{\circ}$ 07).

Para melhor controle, as atribuiçōes permitidas ao atendente de enfermagem são todas transcritas numa folha previamente elaborada, onde a instrutora vai checando à medida que cada aluno executa a tarefa (Anexo n. ${ }^{\circ}$ 08). Este método favorece o reconhecimento do limite das funçōes do atendente e, ao mesmo tempo, possibilita uma melhor visão das oportunidades oferecidas a cada um dos alunos.

Geralmente, os estágios são realizados diariamente, no período da manhā e da tarde, conforme atendimento das solicitaçōes de preferências dos alunos. A conciliação dos horários é observada na medida do possível, considerando que muitos alunos estudam ou trabalham. O estágio é realizado em quarenta e cinco dias úteis, correspondendo a cinco horas diárias. A coordenadora visita algumas vezes o grupo e e comunica-se com a instrutora sempre que necessário.

\section{7 - Avaliação}

No final de cada curso, a coordenadora faz uma apreciação dos campos de estágio, observando sobretudo oportunidades de aprendizagem e relacionamento do pessoal de enfermagem e administrativo. Avalia o programa, principalmente no que se refere à carga horária de cada assunto e ao conteúdo programático, faz portanto, uma análise da aplicação no serviço, dos princípios e técnicas ensinadas durante o curso. Observa as instrutoras em aspectos relacionados a interesse, capacidade de liderança e responsabilidade.

A avaliação dos alunos é iníciada a partir do primeiro dia de aula. Durante o curso teórico, são realizados dois testes com quesitos predominantemente de múltipla escolha; o primeiro, ao término de quarenta horas de aulas e 
AMORIM, M. J. A. B. - A ABEn e o PIPMO no preparo do atendente de enfermagem relato de uma experiência. Rev. Bras. Enf.; DF, 32 : 183-212, 1979.

o segundo, ao término do curso teórico. São observados também a participação do aluno nas aulas teóricas e práticas, a pontualidade, assiduidade e interesse. A partir do primeiro dia de estágio, os critérios de avaliação tornam-se mais intensos e a instrutora passa a registrar em impresso apropriado (Anexo $n{ }^{\circ}$ 09) cada ponto observado. As caracte- rlsticas mais importantes referem-se à responsabilidade, lealdade, atitude, comportamento, assiduidade, pontualidade, interesse, dedicação e iniciativa. A verificação da aprendizagem é determinada em gráus de zero a dez. A nota final do curso é a média aritmética de todas as notas obtidas no estágio, observando-se o seguinte critério:

$\begin{array}{lll}\text { Conceito otimo } & \text { - de } 10 \text { a } 9,0 \text { - aprovado } \\ \text { Conceito Bom } & \text { - de } 8,0 \text { a } 7,0 \text { - aprovado } \\ \text { Conceito Regular } & \text { - de } 6,0 \text { a } 5,0 \text { - aprovado } \\ \text { Conceito Deficiente } & \text { - de } 4,9 \text { ou menos }- \text { reprovado }\end{array}$

III - RESULTADOS

Até a presente data foram preparadas trinta e sete turmas de atendentes de enfermagem, assim distribuidas:

$\begin{array}{lr}\text { Ano } & \text { N.O de T } \\ 1972 & 3 \\ 1973 & 9 \\ 1974 & 5 \\ 1975 & 9 \\ 1976 & 6 \\ 1977 & 2 \\ 1978 & 3\end{array}$

A média foi de 24 alunos por turma, variando entre 19 a 27, perfazendo um total de 902 .

Quanto à idade, estado civil, nacionalidade e nível de escolaridade, encontram-se distribuidos conforme as tabelas que se seguem:

TABELA N. 01 - Idades dos participantes dos cursos de Atendente de Enfer. magem - 1971 - 1978.

\begin{tabular}{rrrrrr}
\hline $\mathrm{X}$ & & $\mathrm{F}$ & $\%$ \\
\hline 17 & $1 / 2$ & $\mathrm{a}$ & 30 & 721 & $80 \%$ \\
31 & $\mathrm{a}$ & 44 & 145 & $16 \%$ \\
+ & & 44 & 36 & $4 \%$ \\
\hline TOTAL & & & & \\
\hline
\end{tabular}


AMORIM, M. J. A. B. - A ABEn e o PIPMO no preparo do atendente de enfermagem relato de uma experiência. Rev. Bras. Enf.; DF, 32 : 183-212, 1979.

TABELA N.o 02 - Estado civil dos participantes dos cursos de Atendente de Enfermagem - 1971 - 1978.

\begin{tabular}{lrr}
\hline $\mathrm{X}$ & $\mathbf{F}$ & $\%$ \\
\hline Solteiro & 739 & $82 \%$ \\
Casado & 144 & $16 \%$ \\
Desquitado & 15 & $1,6 \%$ \\
Viúvo & 4 & $0,4 \%$ \\
& & \\
\hline TOTAL & 902 & $100 \%$ \\
\hline
\end{tabular}

TABELA N. 03 - Nacionalidade dos participantes dos cursos de Atendente de Enfermagem - 1971 - 1978.

\begin{tabular}{lrr}
\hline X & F & $\%$ \\
\hline Brasileiro & 901 & $99,9 \%$ \\
Português & 1 & $0,1 \%$ \\
\hline TOTAL & 902 & $100 \%$ \\
\hline
\end{tabular}

TABELA N. 04 - Nível de escolaridade dos participantes dos cursos de Atendente de Enfermagem - 1971 - 1978.

\begin{tabular}{lrc}
\hline X & F & $\%$ \\
\hline & & \\
$5 .^{\mathrm{a}}$ a $8 .^{\mathrm{a}}$ série & 605 & $64 \%$ \\
$2 .^{\circ}$ grau incompleto & 225 & $25 \%$ \\
$2 .^{\circ}$ grau completo & 68 & $7,5 \%$ \\
Superior incompleto & 4 & $0,5 \%$ \\
\hline
\end{tabular}


AMORIM, M. J. A. B. - A ABEn e o PIPMO no preparo do atendente de enfermagem relato de uma experiência. Rev. Bras. Enf.; DF, 32 : 183-212, 1979.

Quanto à evasão e eliminação de alunos, pode-se observar que houve oitenta e um afastamentos, o que corresponde um pouco mais de dois por turma. As razões quase todas são de ordem social.

\section{IV - ASPECTOS ADMINISTRATIVOS}

A entrega dos certificados é realizada de forma muito simples, quando todos os integrantes do curso já se posicionam acertađamente na equipe de enfermagem, encontrando-se conscientizados quanto à sua situação legal e sua condição de provisionado no Conselho de Enfermagem. Alguns dias antes da data do encerramento, a coordenadora providencia o preparo dos certificados devidamente assinados pelo Coordenador do PIPMO-Ba. e Presidente da ABEn-Ba.

Em livro apropriado com folhas numeradas são realizados os registros de conclusão do curso, conforme exigência do PIPMO.

As enfermeiras instrutoras recebem também um atestado de suas atividades assinado pela Presidente da ABEn-Ba.

A Associação de classe, oportunamen. te, envia ofícios de agradecimento para todos os hospitais utilizados como campo de estágio, assim como relações de concluintes para as entidades onde os cursos foram desenvolvidos.

Inicialmente, eram arquivados na sede da ABEn vários documentos, como relaçōes de concluintes, fichas de avaliação, folhas de freqüência e etc., mas surgiram dificuldades com relação a espaço físico para guarda desse material. Por isso, são preservados somente o livro de registro e relatórios finais dos cursos.

No decorrer do curso, os contatos entre a ABEn e PIPMO são constantes porque muitos documentos são preparados e enviados em atendimento a uma série de exigências burocráticas, como projeto de cursos, relação de alu- nos matriculados, certificados para serem assinados e etc.

Pode-se observar que os serviços dz Secretaria são numerosos e exigirian um funcionário de apoio para o desempenho destas atividades. A verba dispensada para cada curso não permite esta providência, por isso a coordenadora emprega recursos menos dispendiosos, utilizando a própria funcionária da ABEn e outros elementos que são gratificados com alguma quantia.

As formalidades mais complexas no que se refere ao atendimento de exigências administrativas do PIPMO estão voltadas para o setor de contabilidade A prestaçāo de contas deve ser efetuada dentro do prazo estipulado e a sua apresentação obedece a um sistema dis tal forma rigorosa que obriga a participação de profissional competente em contabilidade para que não haja solução de continuidade no processo.

Vale ressaltar que a coordenadora dos cursos é o elemento que incita 0 adiantamento de todas as atividades administrativas exigidas pelo Convênio ABEn/PIPMO, identificando com mais precisão as necessidades, já que se encontra evidentemente envolvida no processo. Esta atuaçāo acrescida das funçōes de coordenadora pedagógica explana a sua competência em inúmeras atribuiçōes (Anexo n.o 10).

evidente que todo o desempenho relacionado a realização dos cursos baseia-se no interesse e esforço manifestados pela Presidente da ABEn porque é ela o elemento que resolve junto ao PIPMO as situaçōes de ordem administrativas que são relativamente freqüentes, é óbvio que sem a sua atuação neste sentido as dificuldades representarão obstáculo na realização dos cursos.

\section{CONCLUSĀO}

Neste trabalho, que aqui é concluido, teve-se oportunidade de apresentar o 
AMORIM, M. J. A. B. - A ABEn e o PIPMO no preparo do atendente de enfermagem relato de uma experiência. Rev. Bras. Enf.; DF, 32 : 183-212, 1979.

cesenvolvimento de um plano de atuacào da ABEn (Associaçāo Brasileira de Enfermagem) junto ao PIPMO (Programa de Preparaçāo de Mão-de-Obra).

O Convênio entre os dois órgãos foi firmado pela primeira vez em 1971 e a partir daí têm sido realizados muitos cursos de Atualizaçāo para Auxiliares de Enfermagem de diversos hospitais de Salvador com treinamento específico em Enfermagem Médico-Cirúrgico, Pediátrica, Obstétrica e de Saúde Pública.

O preparo de atendentes de enfermagem foi igualmente assumido pela ABEn. Anualmente sāo promovidos contatos com determinadas entidades como Centros Sociais, Abrigos, Asilos e etc. e selecionadas aquelas que apresentam condições para a realização dos cursos.

Os trabalhos de divulgaçāo e inscricāo sāo efetuados pelas entidades eleitas que utilizam os seus próprios recursos. A seleçāo consta de provas de Português e Matemática e em segunda etapa, de uma entrevista com cada um dos candidatos aprovados nas referidas provas.

As enfermeiras instrutoras são orientádas pela Coordenaçāo para que haja nma metodologia uniforme. O programa é revisto anualmente com a finalidade cie melhor atender à realidade dos Serviços que absorvem a maior quantidade de concluintes. Como critério de avaliaçāo, considera-se dentre vários as pectos, sobretudo a responsabilidade do aluno no campo de estágio.

No final do curso, todos os integrantes encontram-se conscientizados quanto à sua situaçāo na equipe de enfermagem e à sua condiçāo de provisionado do COREN.

Muitos hospitais usados como campo de estágio convidam imediatamente alguns destes atendentes para os seus serviços. Sabe-se que a grande maioria do pessoal preparado pela ABEn encon- tra-se em Salvador e em algumas cidades do interior. Houve tentativa de comunicação com os egressos mas vários motivos impossibilitaram a satisfaçāo deste plano, principalmente mudança de endereço e falta de condições de ser mantido um funcionário para recebê-los.

Ressalta-se, no entanto, que os contatos que surgem espontaneamente com chefes de serviços de Enfermagem de diversos hospitais e clínicas do Estado da Bahia oferecem motivos para avaliar os objetivos do curso e os seus resultados como elementos positivos para a classe.

\section{RECOMENDAÇOES}

\section{Considerando:}

1 - Que o PIPMO oferece recursos para a promoção de cursos de atualizaçāo para Auxiliares de Enfermagem e preparo do Atendente de Enfermagem;

2 - Que há possibilidade destes recursos serem utilizados por outras entidades para o preparo do Atendente de Enfermagem sem a participação da enfermeira;

3 - Que a organizaçāo destes cursos requer a atuação de uma pessoa com maior disponibilidade de tempo.

\section{Recomenda-se:}

1 - Que cada seçāo da Associaçāo Brasileira de Enfermagem firme Convênio com o PIPMO, solicitando o maior número possivel de cursos;

2 - Que a ABEn convide para a Coordenação dos referidos cursos uma enfermeira que não seja membro de sua Diretoria e que não tenha muitas outras atividades. 
AMORIM, M. J. A. B. - A ABEn e o PIPMO no preparo do atendente de enfermagem relato de uma experiência. Rev. Bras. Enf.; DF, 32 : 183-212, 1979.

\section{ANEXO N. ${ }^{\circ} 01$}

Associação Brasileira de Enfermagem (ABEn)

Programa Intensivo de Preparação de Mão-de-Obra (PIPMO)

RELAÇĀO DO MATERIAL NECESSÁRIO PARA O CURSO DE ATENDENTE DE ENFERMAGEM

1 Cama hospitalar

1 Colchão

1 Travesseiro

1 Encerado

1 Mesa de cabeceira

6 Lençóis

2 Colchas

2 Fronhas

1 Cobertor

2 Pares de luvas atoalhadas

1 Bacia de rosto

1 Balde

1 Jarra

2 Toalhas de banho

2 Toalhas de rosto

12 Folhas de cartolina, pincel atômico em três cores, durex

1 Cartaz do aparelho digestivo

1 Cartaz do aparelho circulatório

1 Cartaz do aparelho respiratório

1 Cartaz do aparelho reprodutor feminino

6 Pares de luvas cirúrgicas

4 Pinças dente de rato

4 Pinças pean

4 Pinças de disseção

5 Metros de papel graft

5 Seringas de $10 \mathrm{cc}$.

5 Seringas de 5 cc.

10 Agulhas $30 \times 8$

1 Vidro de álcool (1 litro)

1 Pacote de algodão (grande)

1 Pacote de gase

1 Rolo de esparadrapo

1 Bandeja

1 Flanela

20 Termômetros

2 Estetoscópios

1 Aparadeira

2 Cubas rim

2 Pinças pean longas

1 Cálice graduado ( 1 ou 2 Ht os)

1 Cálice graduado (20 cc.) 
AMORIM, M. J. A. B. - A ABEn e o PIPMO no preparo do atendente de enfermagem relato de uma experiência. Rev. Bras. Enf.; DF, 32 : 183-212, 1979.

2 Bandejas esmaltadas ou inox (tamanho pequena e média)

1 Saco de borracha (para gelo)

1 Sonda vesical

1 Catéter de 0?,

2 Rolos de atadura (estreita e larga)

1 Sonda retal

1 Sonda naso gástrica

1 Irrigador

15 Folhas de stencyl

1.030 Folhas de papel oficio.

ANEXO N. ${ }^{\circ} 02$

Associação Brasileira de Enfermagem - ABEn

Programa Intensivo de Preparação de Mão-de-Obra - PIPMO

Curso de Atendente de Enfermagem

PROVA DE SELEÇÃo - PORTUGUes

1 - Ditado

2 - Forme frases com as seguintes palavras:

Emergência:

Problema:

Utilidade:

Felicidade:

3 - Passe para o plural as seguintes frases:

a) O rapaz fez boa prova no vestibular.

b) O irmāo de Lúcia trabalha como atendente.

c) Marta trouxe o material solicitado. 
AMIORIM, M. J. A. B. - A ABEn e o PIPMO no preparo do atendente de enfermagem relato de uma experiência. Rev. Bras. Enf.; DF, 32 : 183-212, 1979.

4 - Sublinhe os substantivos das frases abaixo:

a) A casa daquela moça é azul.

b) Arranjei um modelo bonito para o vestido.

c) José ficou feliz com a vitória de Marina.

5 - Passe para o passado as seguintes frases:

a) Luís fará prova de Português.

b) Marta comprará os livros na livraria.

c) Carlos e Eduardo brincarão no carnaval.

6 - Faça duas frases empregando adjetivo composto:

7 - Coloque acento quando necessário:

relampago - cafe - ruido - mensagem - tropego - caju

8 - Coloque os adjetivos pátrios correspondentes:

Europa -

Peru -

Angola -

França -

Pará -

Ilhéus -

\section{ANEXO N. 03}

Associação Brasileira de Enfermagem - ABEn

Programa Intensivo de Preparação de Mão-de-Obra - PIPMO

Curso de Atendente de Enfermagem

PROVA DE SELEÇÃO - MATEMÁTICA

1 - Cite cinco múltiplos de 3 e 2 ao mesmo tempo:

2 - Arme e efetue:

$234,1+98,28+3212,9$

$17324,21-3,901$ 
AMORIM, M. J. A. B. - A ABEn e o PIPMO no preparo do atendente de enfermagem relato de uma experiência. Rev. Bras. Enf.; DF, 32 : 183-212, 1979.

3 - Passe para algarismos romanos:

$$
\begin{array}{lr}
981- & 102- \\
526- & 91-
\end{array}
$$

4 - Escreva os numerais ordinais de:

$$
\begin{array}{ll}
48- & 57- \\
31- & 62-
\end{array}
$$

$5-$ Na subtração $58-31=17$, o número 48 chama-se $\ldots \ldots \ldots \ldots \ldots \ldots \ldots$ 31 chama-se ............... e 17 chama-se

6 - Complete, usando os símbolos ou

$\begin{array}{llllll}243 & \ldots \ldots \ldots \ldots & 143 & 578 & \ldots \ldots \ldots \ldots & 587 \\ 601 & \ldots \ldots \ldots \ldots & 600 & 910 & \ldots \ldots \ldots \ldots & 820\end{array}$

7 - Dê exemplo de um conjunto vazio e um unitário:

8 - Laura recebeu da mãe Cr\$982,00. Comprou um vestido por Cr $\$ 340,00$ e uma carteira por $\operatorname{Cr} \$ 281,00$. Recebeu do tio $\mathrm{Cr} \$ 1.820,00$. Quanto tem agora?

\section{ANEXO N. ${ }^{\circ} 04$}

Associação Brasileira de Enfermagem - ABEn

Programa Intensivo de Preparação de Mão-de-Obra - PIPMO

FICHA PARA AUTO ANALISE DO PROFESSOR

QUALIDADES DO PROFESSOR Ótimo Muito Médio Fraco Insufi-

bom ciente

A - Caracteristicas pessoais:

de doença.

a) Saúde e vigor físico.

b) Falta raras vezes por motivo de doença.

c) Apresenta disposição alegre.

B - Atitude:

a) Equilíbrio emocional.

b) Autocontrole.

c) Autoconfiança.

C - Capacidade de expressão:
a) Voz agradável.
b) Fala naturalmente, sem afe- tação.
e) Não tem vícios de linguagem. 
AMORIM, M. J. A. B. - A ABEn e o PIPMO no preparo do atendente de enfermagem relato de uma experiêncìa. Rev. Bras. Enf.; DF, 32 : 183-212, 1979.

D - Imaginação e versatilidade:

a) rico em recursos para desenvolver uma aula.

b) Sabe adaptar-se, possui amplos horizontes de compreensão.

E - Capacidade de julgamento:

a) Sabe reconhecer os verdadeiros valores.

b) Sabe tomar decisōes e tem op:niōes firmes.

F - Métodos e Técnicas de trabalho:

a) Trabalho planejado e bem organizado.

b) Sabe reconhecer diferenças individuais.

G - Aproveitamento demonstrado pelos alunos:

a) Os alunos demonstram uma sadia atitude de interesse.

b) Há cooperação, tolerância, cortesia e participação entre os alunos.

$\mathrm{H}$ - Relações profissionais:

a) Contribui para a eficiência do curso.

b) membro atuante na Associação de classe.

ANEXO N.O 05

PROGRAMA DO CURSO DE ATENDENTE DE ENFERMAGEM

Associação Brasileira de Enfermagem - ABEn

Programa Intensivo de Preparação de Mão-de-Obra - PIPMO

Coordenadora: Maria José Arléo Barbosa Amorim

Total de horas teóricas - 75 (5 horas destinadas a revisāo e avaliação)

Total de horas práticas - 225 (estágio em hospitais) 
AMORIM, M. J. A. B. - A ABEn e o PIPMO no preparo do atendente de enfermagem relato de uma experiência. Rev. Bras. Enf.; DF, 32 : 183-212, 1979.

\title{
OBJETIVOS:
}

\section{1 - Comportamento Terminal:}

- O Atendente de Enfermagem deverá estar apto a aplicar tarefas elementares de enfermagem, sobretudo aquelas situadas no campo da esfera doméstica.

\author{
2 - Intermediários: \\ O aluno deverá: \\ - Posicionar-se corretamente na equipe de enfermagem. \\ - Identificar sua condição futura de provisionado no Con- \\ selho de Enfermagem. \\ - Reconhecer o limite de suas atribuiçōes na área hos- \\ pitalar.
}

OBSERVAÇÃO - No Estado da Bahia e mesmo Salvador, o número de auxiliares de enfermagem preparado anualmente não atende à grande demanda no mercado de trabalho, portanto a realidade dos Serviços que absorvem a maior quantidade de concluintes apresenta peculiaridades locais. Em decorrência deste fato, houve necessidade de serem acrescidos ao programa, em reunião de Diretorıa da ABEn em 1972, algumas técnicas que fogem às atribuições do Atendente de Enfermagem.

N. ${ }^{\circ}$ de alunos

Local de realização -

Data do início

Data do término -

Nome do Instrutor -

\begin{tabular}{|c|c|c|c|c|c|}
\hline Conteúdo & Programático & $\begin{array}{c}\text { Carga } \\
\text { horária }\end{array}$ & Estratégia & Recursos & $\begin{array}{l}\text { Dia } \\
\text { mês }\end{array}$ \\
\hline
\end{tabular}

- Equipe de saúde

- Equipe de Enfermagem. Situaçã.o do Atendente. Seu posicionamento

2 Exposiçāo dialogada

Quadro giz textos

no Conselho de Enfermagem.

- Direitos e deveres do Atendente como funcionário. Aparência pessoal. comportamento, guarda do sigilo.
Quadro giz, textos Código de Deantologia e de Processo tico 
AMORIM, M. J. A. B. - A ABEn e o PIPMO no preparo do atendente de enfermagem relato de uma experiência. Rev. Bras. Enf.; DF, 32 : 183-212, 1979.

\begin{tabular}{cclc}
\hline \multicolumn{1}{c}{ Conteúdo Programático } & $\begin{array}{c}\text { Carga } \\
\text { horária }\end{array}$ & Estratégia & $\begin{array}{c}\text { Recursos } \\
\text { mês }\end{array}$ \\
\hline $\begin{array}{l}\text { Preparo de material p/TPR - Téc- } \\
\text { níca de verificação - Elaboração } \\
\text { do gráfico. }\end{array}$ & $\begin{array}{l}\text { Demonstração } \\
\text { com devolução } \\
\text { de técnica }\end{array}$ & $\begin{array}{l}\text { Bandeja, termô- } \\
\text { metro, recipiente } \\
\text { com solução (pa- } \\
\text { ra o termômetro), } \\
\text { relógio, impresso }\end{array}$ \\
\hline
\end{tabular}

- Higiene oral - Higiene das mãos 1 Demonstração e rosto.

Escova de dentes Bacia de rosto cuba - rim, solução dentifricia, toalha de rosto, espátula, bolos alg.

\begin{tabular}{lll}
\hline Banho de leito - Higiene intima. & $4 \begin{array}{l}\text { Demonstração } \\
\text { com devolução } \\
\text { va, mudança de decúbito. Oferecer }\end{array}$ & $\begin{array}{l}\text { Roupa de cama, } \\
\text { de técnica }\end{array}$ \\
$\begin{array}{l}\text { bacia, jarra com } \\
\text { água, toalha de } \\
\text { banho, luva atoa- } \\
\text { lhada, sabonete, } \\
\text { pente, balde. }\end{array}$
\end{tabular}

- Prevençāo de escaras e deformi- Demonstraçāo Soluçāo lubrifidades. cante, ataduras

- Higiene dos cabelos. Toilete da 2 Demonstração tarde.

Encerado, balde, sabonete, jarra. Material de higiene oral

- Auxílio ao paciente durante a ali-

2 Demonstraçāo

Quadro giz, mentação. Fatores que influenciam cartazes na apetite. Apresentação dos alimentos.

- Participação do atendente de enfermagem no exame físico - Posiçỏes para exame.
3 Exposição e demonstração
Martelo de percussão, tensiômetro, estetoscópio, bandeja, termômetro, cartazes
- Transporte de paciente em maca e cadeira de rodas - Auxílio do paciente na ambulância.
2 Exposição e demonstração
Quadro giz Cartazes
- Controle de líquidos ingeridos eliminados.
2 Exposição e demonstração
Cálice graduado.

Copo graduado 
AMORIM, M. J. A. B. - A ABEn e o PIPMO no preparo do atendente de enfermagem relato de uma experiência. Rev. Bras. Enf.; DF, 32 : 183-212, 1979.

$\begin{array}{llll}\text { - Colheita de material para exame } & \text { Exposição } & \text { Recipiente } \\ \text { de laboratório (fezes - urina e es- } \\ \text { carro). }\end{array}$

- Noções de medicamentos - tipos $6 \begin{aligned} & \text { Exposição e } \\ & \text { demonstração }\end{aligned}$
$\begin{aligned} & \text { e vias de administração. } \\ & \text { - via oral }\end{aligned}$
- supositório
- Instilação nos olhos, ouvidos e
$\quad$ nariz.

- Curativos simples

2 Demonstração

Pinças pean, disseção e dente de rato; algodão, gase e esparadrapo

\begin{tabular}{|c|c|c|c|}
\hline $\begin{array}{l}\text { - Aplicação de bolsa de água quente } \\
\text { e bolsa de gelo. }\end{array}$ & 1 & Demonstração & $\begin{array}{l}\text { Bolsa de água } \\
\text { e de gelo }\end{array}$ \\
\hline - Lavagem intestinal e clister & 2 & Exposição & $\begin{array}{l}\text { Solução usada pa- } \\
\text { ra lavagem tipo } \\
\text { glicerinada }\end{array}$ \\
\hline $\begin{array}{l}\text { - Aplicação de 0- Cuidado com } \\
\text { umidificadores. }\end{array}$ & 1 & Exposição & Quadro giz \\
\hline - Restriçōes de movimentos. & 1 & Demonstração & Ataduras \\
\hline - Assistência ao paciente na alta. & 1 & Exposição & Quadro giz \\
\hline $\begin{array}{l}\text { - Cuidado com o corpo pós-morte. } \\
\text { Remoção de cadáveres. }\end{array}$ & 1 & Exposição & Quadro giz \\
\hline
\end{tabular}

\footnotetext{
OBSERVAÇÓES - As cinco horas de revisao e avalição podem ser usadas conforme necessidade do grupo e planejamento do instrutor. Após a conclusão desta etapa, os alunos serão distribuidos em grupos para estágios.
} 
AMORIM, M. J. A. B. - A ABEn e o PIPMO no preparo do atendente de enfermagem relato de uns experiência. Rev. Bras. Enf.; DF, 32 : 183-212, 1979.

\section{BIBLIOGRAFIA}

1. AMORIM, Maria José Arléo Barbosa e NUNEZ, Rosamaria Silva - Apostilas elaboradas para o curso de Atendente de Enfermagem, Convênio ABEn/PIPMO - 1971.

2. AMORIM, Maria José Arléo Barbosa Apostila elaborada para o Concurso de Auxiliar Operacional, nivel 3 DASP.

3. ABDALLAH, Mary C. - Manual para la Auxiliar de Enfermeria. Ed. Interamericana, S.A. $-1 \mathrm{r} 67$.

4. CAMARGO, Maria Lúcia Alves - Curso Prático de Auxiliar de Enfermagem - Editora e Encardenadora Lumen Ltda.

5. CRUZ, Enede Andrade - Princípios de Esterilização e Desinfecção em uni hospital. Apostila para Auxiliar e Atendente de Enfermagem, Ba. 1974.
6. HENDERSON, Virginia - Tratado de Enfermería teórica y práctica - La Prensa Médica Mexicana; México 2. ${ }^{\mathrm{a}}$ Edição - 1959.

7. KOCH, Rosi M. et alli - Técnicas Básicas de Enfermagem - Ed. Gráfica Voz do Panará Ltda. - Curitiba $1977-5 .^{\mathrm{a}}$ edição.

8. LUCKESI, Maria Antonieta e NUNEZ, Rosamaria Silva - Apostilas elaboradas para treinamento de A.O. Setor de Treinamento - Hospital Ana Nery.

9. SOUZA, Elvira de Felice - Novo Manual de Enfermagem. Ed. Bruno Buccini - 1972 - Rio de Janeiro G.B.

10. TEIXEIRA, Ruth Borges e colaboradores - Manual do Auxiliar de Enfermagem - Associação Brasileira de Enfermagem - 1966 - Rio de Janeiro.

\section{ANEXO N.0 06}

Associação Brasileira de Enfermagem - ABEn

Programa Intensivo de Preparação de Mão-de-Obra - PIPMO

Curso de Atendente de Enfermagem

PROVA DE AVALIAÇĀO

I - Marque com um X a resposta certa:

1. Dentre os deveres do Atendente de Enfrmagem para com o paciente incluem-se:

( ) manter familiaridade

( ) censurar diante de suas reações

( ) incentivá-lo a posicionar-se politicamente

( ) proporcionar ao paciente o devido conforto físico

2. Legalmente, a equipe de enfermagem é composta por:

( ) enfermeiro, técnico e auxiliar de enfermagem

( ) enfermeiro, atendente de enfermagem, médico

( ) auxiliar, nutricionista, fisioterapeuta

( ) enfermeiro, técnico e atendente de enfermagem 
AMORIM, M. J. A. B. - A ABEn e o PIPMO no preparo do atendente de enfermagem relato de uma experiência. Rev. Bras. Enf.; DF, 32 : 183-212, 1979.

3. Como sinônimo de febre, podemos dizer:
( ) bradicardia
( ) pixeria
( ) hiperpnéia

4. A temperatura normal de uma pessoa é em torno de:

$$
\begin{array}{lll}
\text { ( ) } 35^{\circ} \text { a } 37^{\circ} \\
\text { ( ) } 36^{\circ} \text { a } 38^{\circ} \\
\text { ( ) } 36^{\circ} \text { a } 37^{\circ} \\
\text { ( ) } 35^{\circ} \text { a } 36^{\circ}
\end{array}
$$

5. A pulsação de um adulto normal é em torno de quantos batimentos por minuto?

$$
\begin{array}{rrrr}
\text { ( ) } & 70 \text { a } & 110 \\
\text { ( ) } & 60 \text { a } & 90 \\
\text { ( ) } & 40 \text { a } & 70 \\
\text { ( ) } & 80 \text { a } & 130
\end{array}
$$

6. A respiração normal que no adulto é em torno de 16 a 20 movimentos por minuto, chama-se:
( ) dispnéia
( ) apnéia
( ) ortopnéia
( ) eupnéia

7. O leito hospitalar que não está sendo utilizado pelo paciente chamase:
( ) aberto
( ) ocupado
( ) fechado
( ) vazio

8. A limpeza da unidade deve ser feita obrigatoriamente:

( ) após alta, transferência ou óbito

( ) quando o paciente se ausenta para fazer algum exame

( ) depois que as visitas saem do hospital

( ) nos feriados e dias de domingo

9. A roupa usada deve ser colocada:
( ) no sanitário
( ) na mesa de cabeceira
( ) no hamper
( ) na porta da enfermaria 
AMORIM, M. J. A. B. - A ABEn e o PIPMO no preparo do atendente de enfermagem relato de ums experiência. Rev. Bras. Enf.; DF, 32 : 183-212, 1979.

10. Dentre os materiais usados para o exame físico, citamos:

( ) jarra com água, bacia de rostos, termômetro

( ) estetoscópio, aparadeira, papel higiênico

( ) abaixador de lingua, papagaio, bacia

( ) martelo de percussão, abaixador de lingua, tensiómetro

11. Um pacote de curativo deve conter principalmente:

( ) pinça pean, pinça anatômica, dissecção e tentacânula

( ) água oxigenada, soro fisiológico, pinças, bolas de algodão

( ) cuba-rim, esparadrapo, pinças, bolas de algodão

( ) pinça anatōmica, éter, bolas de algodāo

12. Os principais meios de prevenção de escaras em paciente acamado são:

( ) massagens, mudanças de posição

( ) higiene oral e toalete da tarde

( ) limpeza das unhas e movimentação passiva

( ) exercícios e assistência de apoio

13. Dentre os meios de proporcionar conforto ao paciente acamado, citamos:

( ) deambulação precoce, assistência de apoio

( ) limpeza dos cabelos e das unhas

( ) banho no leito, mudança de posição e higiene oral

( ) isolamento do leito, proibição de vísitas e exercícios

14. A toalete da tarde consta principalmente de:

( ) higiene dos cabelos, arrumação do leito, massagens

( ) deambulação, arrumação da unidade

( ) banho no leito, exercícios respiratórios, mudança de lençóis

( ) higiene intima e oral, massagens, arrumação do leito

15. As regiōes mais propícias à formação de escaras são:

( ) glúteo, sacro, ponta do omoplata, calcanhar

( ) cabeça, pernas e braços

( ) região abdominal e coxas

( ) pontas dos dedos, queixo e orelhas

16. O ambiente e o estado emocional do paciente sāo fatores que:
( ) não têm significado
( ) influem no apetite
( ) dificultam a recuperação
( ) irritam o paciente 
AMORIM, M. J. A. B. - A ABEn e o PIPMO no preparo do atendente de enfermagem relato de uma experiência. Rev. Bras. Enf.; DF, 32 : 183-212, 1979.

17. O paciente se mantém sobre o peito e o joelho. O nome desta posição é:
( ) Fawler
( ) Trendelemburg
( ) ginecológica
( ) genupeitoral

18. Rótulo contendo nome do paciente, nome da enfermaria, número do leito, tipo de material. Deve ser colocado:
( ) no pacote de material esterilizado
( ) no corpo do cadáver
( ) no recipiente para exame de fezes e urina
( ) no leito do paciente

19. Devido o relaxamento de esfincteres, deve-se ter o seguinte cuidado com o corpo do recém-morto:
( ) tamponar as cavidades
( ) fechar os olhos
( ) colocar a etiqueta de identificação
( ) amarrar a mandíbula com uma atadura

20. A destruição de qualquer tipo de micro-organismo chama-se:

$$
\begin{aligned}
& \text { ( ) contaminação } \\
& \text { ( ) esterilização } \\
& \text { ( ) desinfecçāo } \\
& \text { ( ) antisséptico }
\end{aligned}
$$

II - Complete as lacunas:

21. Substância química capaz de inibir o crescimento e proliferação dos germes chama-se:

22. Para haver esterilizaçāo pelo calor, deve-se levar em consideração:

23. A estufa é o aparelho usado para esterilizar através do calor:

24. As roupas devem ser esterilizadas em:

25. O prontuário é composto dos seguintes elementos: 
AMORIM, M. J. A. B. - A ABEn e o PIPMO no preparo do atendente de enfermagem relato de uma experiência. Rev. Bras. Enf.; DF, 32 : 183-212, 1979.

III - Numere a $1 .^{\mathrm{a}}$ coluna de acordo com a $2 .^{\mathrm{a}}$ :

26. ( ) bradicardia

( ) taquipnéia

( ) taquicardia

( ) apnéia

( ) dispnéia

27. ( ) lavagem intestinal

( ) hipertemia

( ) sigilo profissional

( ) banho no leito

( ) sangue arterial
1. respiração rápida

2. pulso rápido

3. dificuldade de respirar

4. parada respiratória

5. respiração lenta

1. meio de proporcionar conforto

2. posição de Sims

3. febre alta

4. segredo confiado

5. coração esquerdo

IV - Numere de acordo com a seqiiência de cuidados:

28. Na deambulação do paciente que ficou muito tempo acamado ou que foi operado, a ordem dos cuidados deve ser:

( ) sentá-lo numa cadeira próxima ao leito

( ) ajudá-lo a descer do leito

( ) colocar a cama em Fowler

( ) sentar o paciente no leito

( ) andar com ele, seguran do-o

( ) trazê-lo de volta ao leito

29. Ao receber o paciente numa sala de exames o atendente deve obedecer a seguinte ordem de cuidados:

( ) ajudar o paciente a trocar de roupa

( ) colocá-lo em posição adequada

( ) ausentar-se discretamente durante a anamnese

( ) recebê-lo gentilmente, encorajando-o

V - Responda resumidamente.

30. O que entende por paciente? 
AMORIM, M. J. A. B. - A ABEn e o PIPMO no preparo do atendente de enfermagem relato de uma experiência. Rev. Bras. Enf.; DF, 32 : 183-212, 1979.

\section{ANEXO N.O 07}

Associação Brasileira de Enfermagem - ABEn

Programa Intensivo de Preparação de Mão-de-Obra - PIPMO

Curso de Atendente de Enfermagem

FOLHA DE FREQUENCIA AOS ESTAGIOS

DATA ASSINATURA HORA/ENTRADA HORA/SAIDA

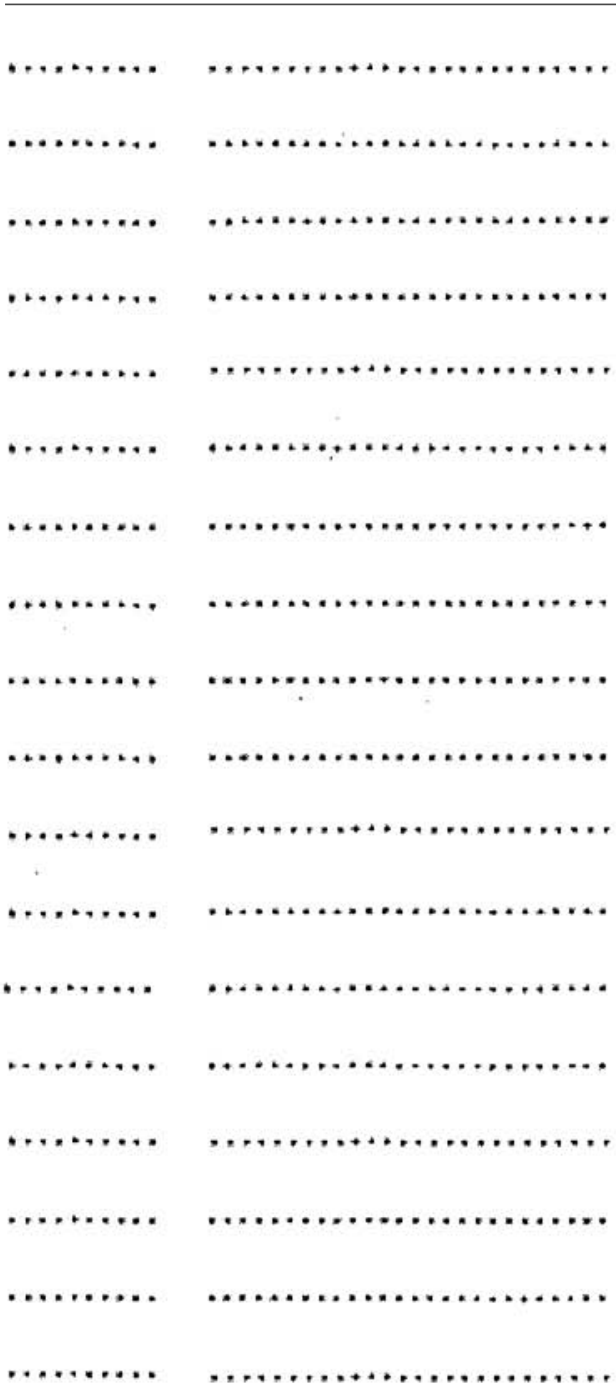


AMORIM, M. J. A. B. - A ABEn e o PIPMO no preparo do atendente de enfermagem relato de ums experiência. Rev. Bras. Enf.; DF, 32 :183-212, 1979.

\section{ANEXO N. ${ }^{\circ} 08$}

Associação Brasileira de Enfermagem - ABEn

Programa Intensivo de Preparação de Mão-de-Obra - - PIPMO

Curso de Atendente de Enfermagem

CONTROLE DE EXECUÇAO DE TAREFAS NO ESTÁGIO

TAREFAS

Preparo de unidade
Verificação de temperatura
Verificação de pulso
Verificação de respiração
Verificação de TA
Verificação de peso
Verificação de estatura

Ajuda ao paciente na deambulação

Ajuda ao paciente na alimentação

Eanho no leito

Movimentação passiva

Mudança de decúbito

Higiene oral

Higiene intima

Preparo de luvas para esterilização

Preparo de seringas para esterilização

Prenaro de material de curativo

Transporte do paciente em cadeira de rodas

Transporte do paciente em maca

Colheita de urina para exames

Colheita de fezes para exames

Aplicação quente

Aplicação fria

Colocar o paciente em posição de Sims

Colocar o paciente em posição ginecológica

Em posiçâo genupeitoral

Em posição de Fowler

Colocar o paciente na aparadelra

Atendimento ao médico e ao paciente durante o exame físico

Admissão do paciente

Alta do paciente

Lavagem intestinal
A L U N AS

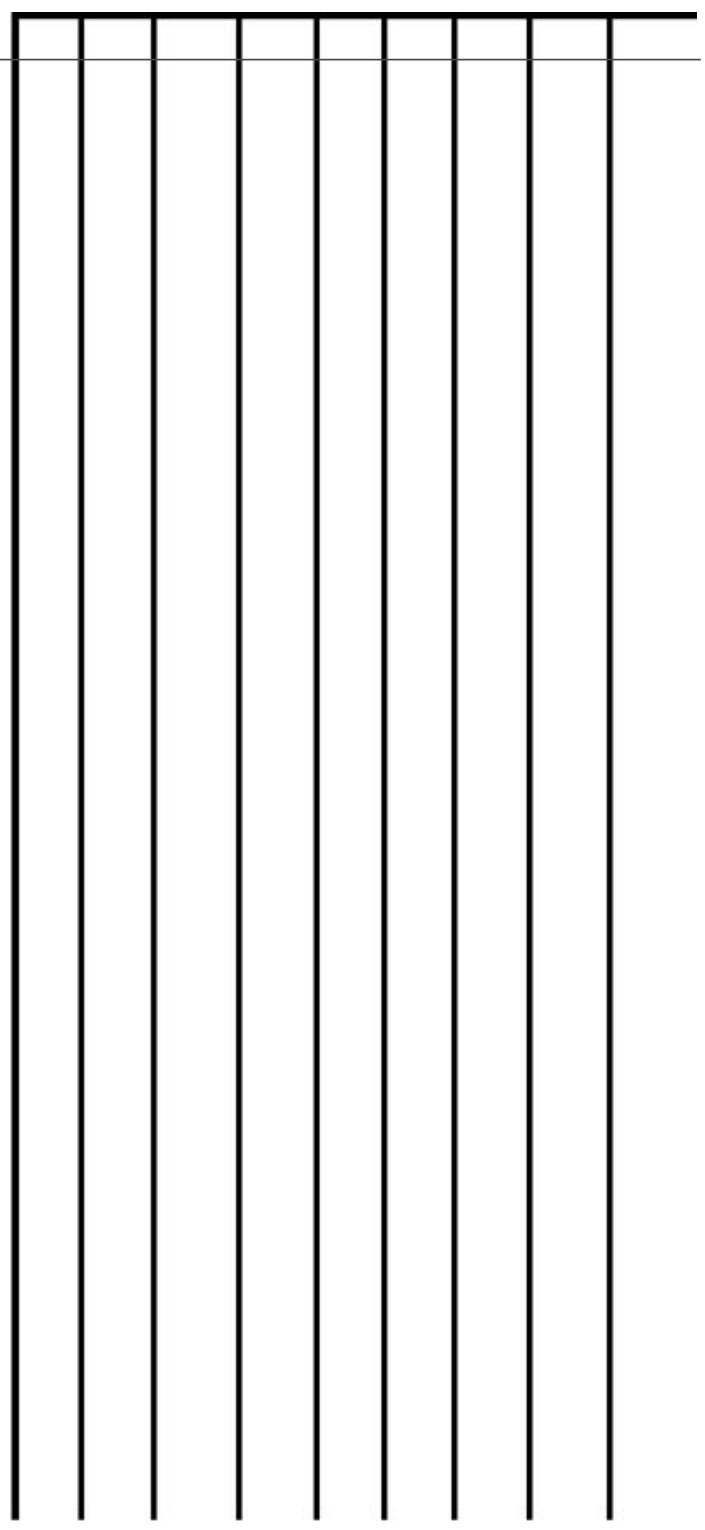


AMORIM, M. J. A. B. - A ABEn e o PIPMO no preparo do atendente de enfermagem relato de uma experiência. Rev. Bras. Enf.; DF, 32 : 183-212, 1979.

TAREFAS

Curativo simples

Tricotomia

Preparo do corpo pós morte

Preparo de cama aberta

Preparo de cama fechada

Preparo de cama de operado

Higiene dos cabelos

Acompanhamento do paciente para exame

Controle de líquidos ingeridos e eliminados

Medicação por via oral

Por via retal (supositório)

Higiene das unhas

Anotaçōes em prontuário

Gráfico de TPR

Toilete da tarde
A L U N AS

\begin{tabular}{|l|l|l|l|l|l|l|l|l}
\hline & & & & & & & & \\
\hline & & & & & & & & \\
& & & & & & & & \\
& & & & & & & & \\
\end{tabular}

\section{ANEXO N..$^{\circ} 09$}

Associaçāo Brasileira de Enfermagem - ABEn

Programa Intensivo de Preparação de Mão-de-Obra - PIPMO

Curso de Atendente de Enfermagem

FOLHA DE AVALIAÇAOO DO ALUNO

ótimo

Bom Regular

Deficiente

Atitude em serviço

Responsabilidade

Pontualidade

Assiduidade

Eficiência

CONCEITO GLOBAL:

Assinatura do Instrutor

Assinatura do aluno

Otimo

Bom
- 10 e 9 pontos

- 8 e 7 pontos
Regular

Deficiente
- 6 e 5 pontos

- 5 pontos 
AMORIM, M. J. A. B. - A ABEn e o PIPMO no preparo do atendente de enfermagem relato de uma experiência. Rev. Bras. Enf.; DF, 32 : 183-212, 1979.

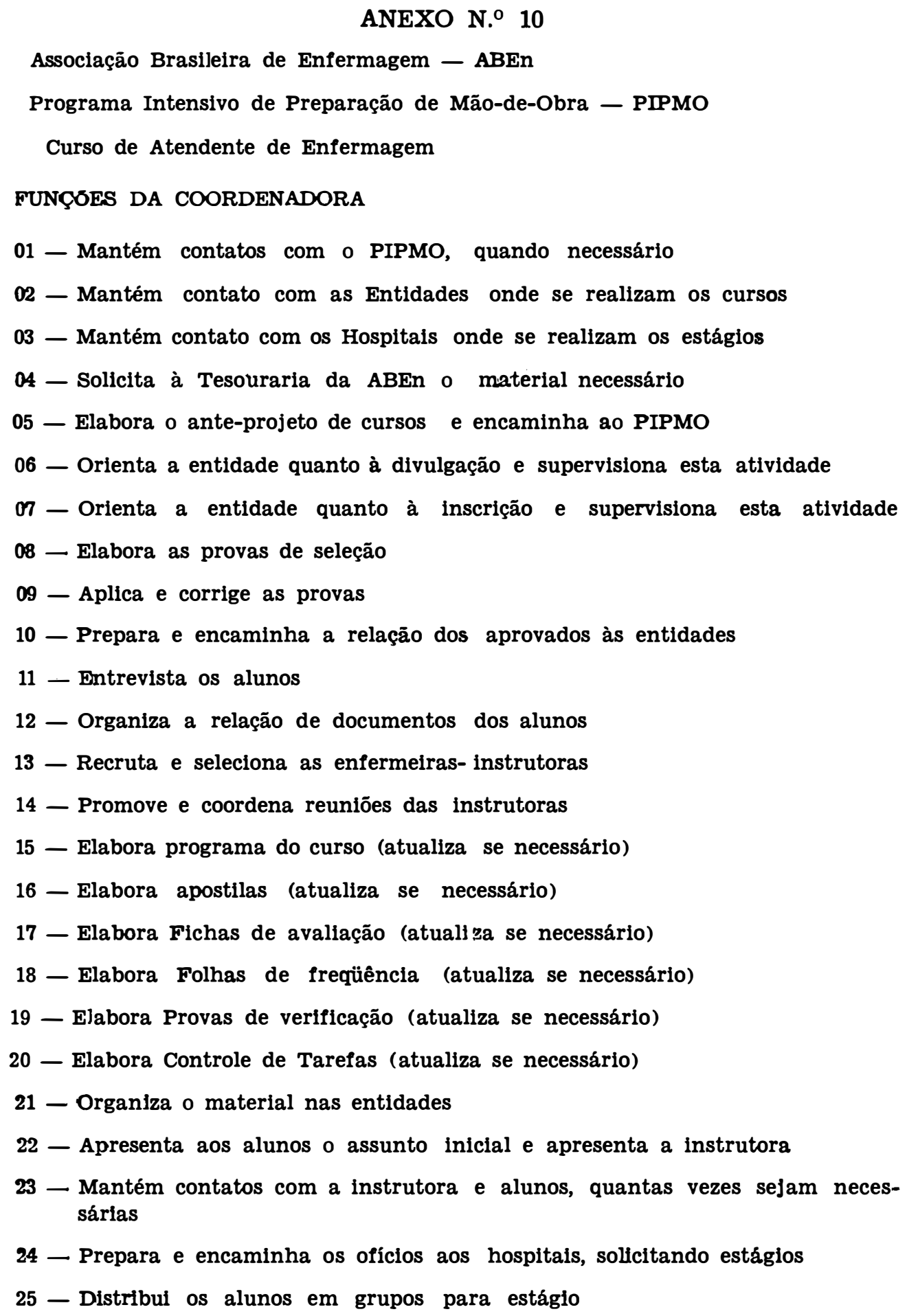
sárias 
AMORIM, M. J. A. B. - A ABEn e o PIPMO no preparo do atendente de enfermagem relato de uma experiência. Rev. Bras. Enf.; DF, 32 :183-212, 1979.

26 - Decide sobre uniformes o orienta os alunos na aquisiçãa dos mesmos

27 - Orienta os alunos sobre o material usado para estágio e atitude durañte sua realização

28 - Visita a instrutora e alunos nos hospitais quantas vezes sejam necessárias

29 - Apresenta os resultados do curso aos alunos

30 - Orienta a Secretária da ABEn para preparo dos certificados

31 - Realiza a entrega dos certificados

32 - Prepara os documentos a serem enviados para o PIPMO (RAT, Relatório de Turma Concluída)

33 - Elabora relatório final e encaminha à ABEn

34 - Envia relação de concluintes para as entidades.

\section{BIBLIOGRAFIA}

01. BASS, Bernardo e Vaughan, James O Aprendizado e o Treinamento na Indústria - Ed. Atlas S/A - Såo Paulo.

02. CAMARGO, Marculino - tica, Vida e Saúde - Ed. Vozes Ltda., 1975 Petrópolis.

03. FERREIRA, Paulo Pinto - Treinamento de Pessoal - Ed. Atlas S/A - São Paulo - 1975.

04. FONTES, Lauro Barreto - Manual do Treinamento na Empresa Moderna
- Ed. Atlas S/A - Săo Paulo - 2." Ediçåo.

05. FURTHR, Pierte - Educação e Vida Ed. Vozes IImitada, 6." Edição.

06. SPERB, Dalila C. - Administração e Supervisão Escolar - Ed. Globo Porto Alegre - 1976 - 3." Ediçăo.

07. VIANNA, Heraldo Marelin - Testes em Educaçáo - Ed. Ibrasa, Sảo Paulo - 1973. 